\title{
SICKLE RETINOPATHY IN PATIENTS WITH SICKLE TRAIT
}

\author{
H. JACKSON ${ }^{1}$, C. R. BENTLEY ${ }^{1}$, M. HINGORANI ${ }^{2}$, P. ATKINSON ${ }^{2}$, W. A. ACLIMANDOS ${ }^{2}$ \\ and G. M. THOMPSON ${ }^{1}$ \\ London
}

\begin{abstract}
SUMMARY
Sickle trait is traditionally considered a benign condition by ophthalmologists. Three cases of sickle retinopathy in subjects with sickle trait are reported. In all cases the onset of retinopathy was related to other contributing factors: in one case a traumatic hyphaema and raised intraocular pressure, in two others diabetes mellitus. Patients with sickle trait are at risk of retinopathy if coincident ocular or systemic disease is present.
\end{abstract}

Sickle trait is the commonest of the sickle haemoglobinopathies and affects approximately $9 \%$ of the Afro-Caribbean population of North America. ${ }^{1}$ Traditionally the condition was considered to be benign, important only for its genetic implications, ${ }^{2,3}$ but some authors have challenged this viewpoint. Spontaneous vitreous haemorrhage, ${ }^{3,4}$ proliferative retinopathy ${ }^{5}$ and other ocular lesions have been described, albeit in the presence of some precipitating factor.

Factors known to enhance sickling of red blood cells, thereby increasing the risk of vascular thrombosis, include hypoxia, dehydration, acidosis, hyperviscosity and the percentage of abnormal haemoglobin. ${ }^{6}$ The combination of sickle trait and a significant degree of one or more of these factors may provoke sickle retinopathy. Three cases are reported to emphasise the importance of considering sickle trait as relevant to the management of eye disease in at-risk patients.

\section{CASE REPORTS}

Case 1

A 14-year-old previously healthy Ghanaian boy

From: ${ }^{1}$ St George's Hospital, London; ${ }^{2}$ King's College Hospital, London, UK.

Correspondence to: Mr C. R. Bentley, FRCOphth, Department of Neuro-Ophthalmology, The National Hospital for Neurology and Neurosurgery, Queen Square, London WC1N 3BG, UK. presented to the eye casualty having been hit in the left eye by a paper pellet. On examination the vision was right $6 / 5$ and left $6 / 18$. On the left side a $5 \mathrm{~mm}$ hyphaema was present, the pupil was round and reactive and the intraocular pressure (IOP) was 18 $\mathrm{mmHg}$. Dilated funduscopy was normal. The following day the hyphaema had reduced in size but the IOP had risen to $38 \mathrm{mmHg}$, hence topical and oral ocular antihypertensive agents were introduced. Haemoglobin $(\mathrm{Hb})$ electrophoresis revealed AS sickle trait with an $\mathrm{HbS}$ concentration of $38.3 \%$. The next day the IOP had risen to $53 \mathrm{mmHg}$ and oral glycerol was added to the regime. There was good response to this treatment, with the IOP returning to normal and gradual resolution of the hyphaema. Gonioscopy confirmed angle recession nasally.

Six days after admission the patient was noted to have scattered preretinal and subhyaloid haemorrhages in the temporal mid-periphery, but no retinal tears were identified. After 14 days the visual acuity was $6 / 6-3$, the eye was quiet with no hyphaema and the IOP was $13 \mathrm{mmHg}$. The haemorrhages in the mid-periphery remained and occluded vessels involving almost all of the peripheral retina were seen (Fig. 1). Six weeks after the incident the haemorrhages had resolved but there was no change in the appearance of the peripheral vasculature. A fluorescein angiogram (Fig. 2) showed extensive peripheral occlusion but no neovascularisation.

The other fundus is normal and the IOP has remained at $12-15 \mathrm{mmHg}$ on no treatment.

\section{Case 2}

A 59-year-old Jamaican woman was referred from the diabetic clinic because of reduced visual acuity and the finding of background diabetic retinopathy. She had been an insulin-dependent diabetic for 30 years, hypertension had been diagnosed 4 years previously and this was well controlled on nifedipine and a diuretic. She did not smoke. Visual acuity was 


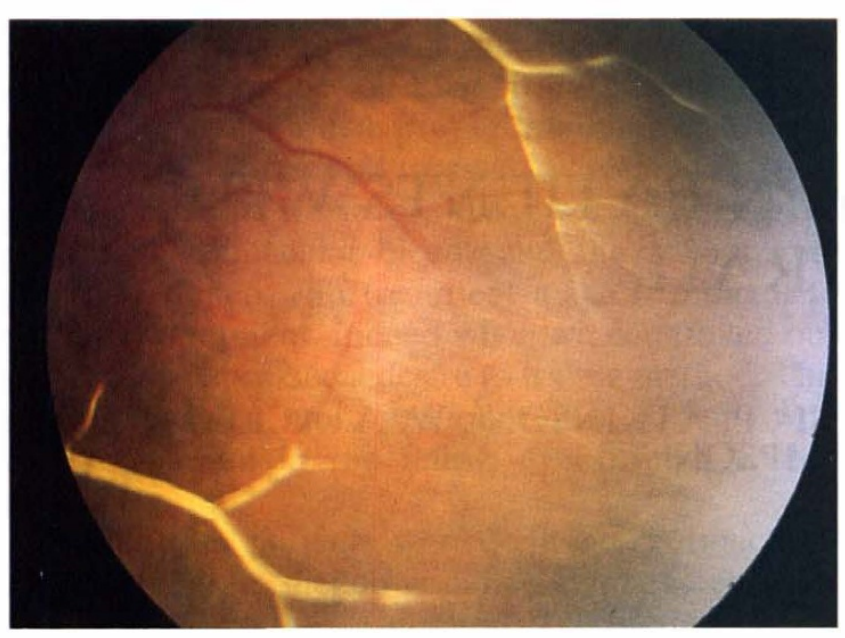

Fig. 1. Case 1. Occluded vessels in peripheral retina.

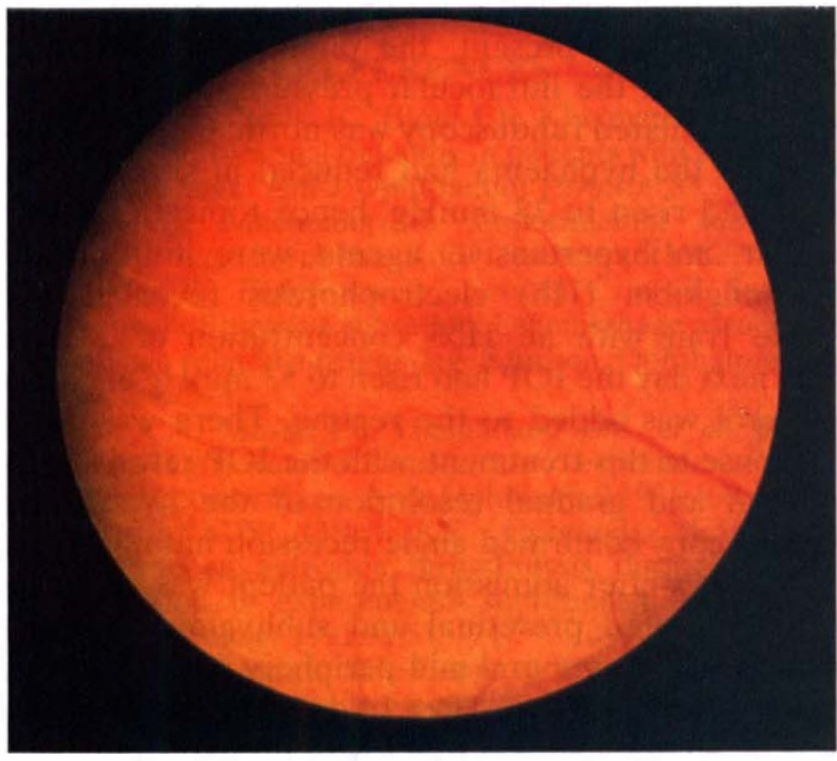

Fig. 3. Case 2. Peripheral vascular occlusion with sea-fans.

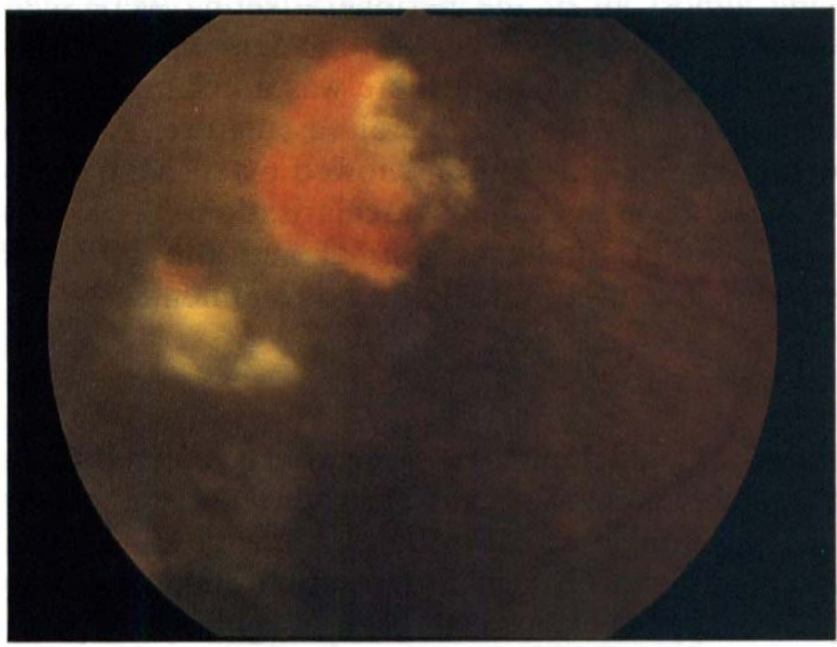

Fig. 5. Case 3. Marked peripheral sea-fan neovascularisation.

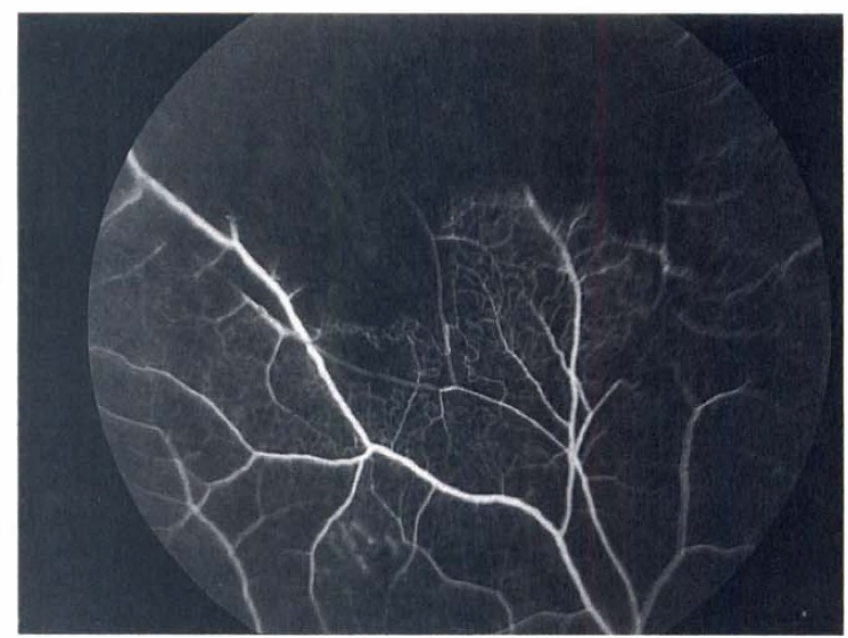

Fig. 2. Case 1. Extensive peripheral vascular closure without neovascularisation.

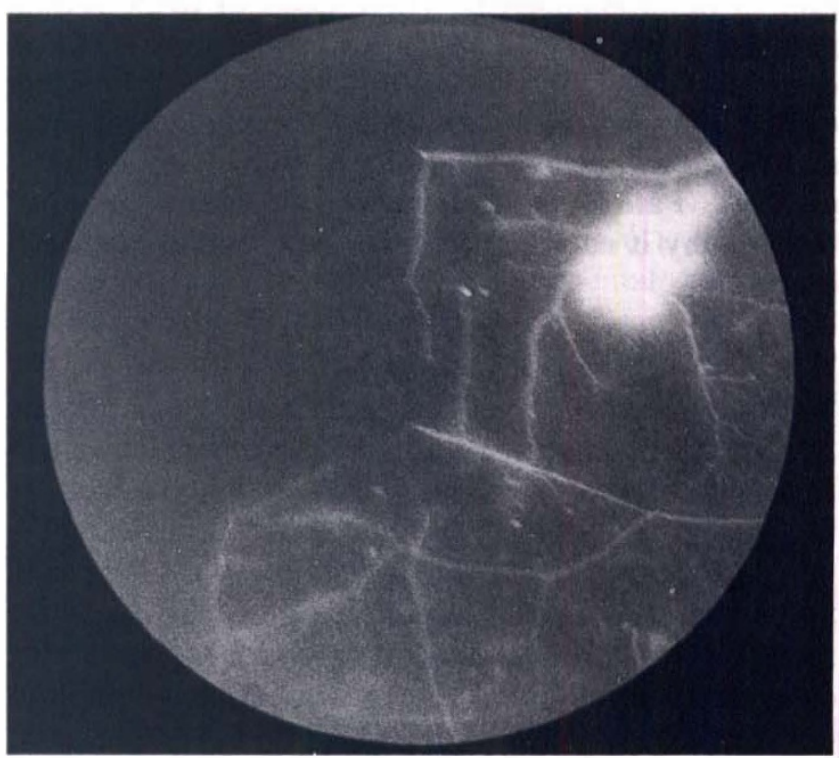

Fig. 4. Case 2. Ischaemia with perfused and infarcted seafans.

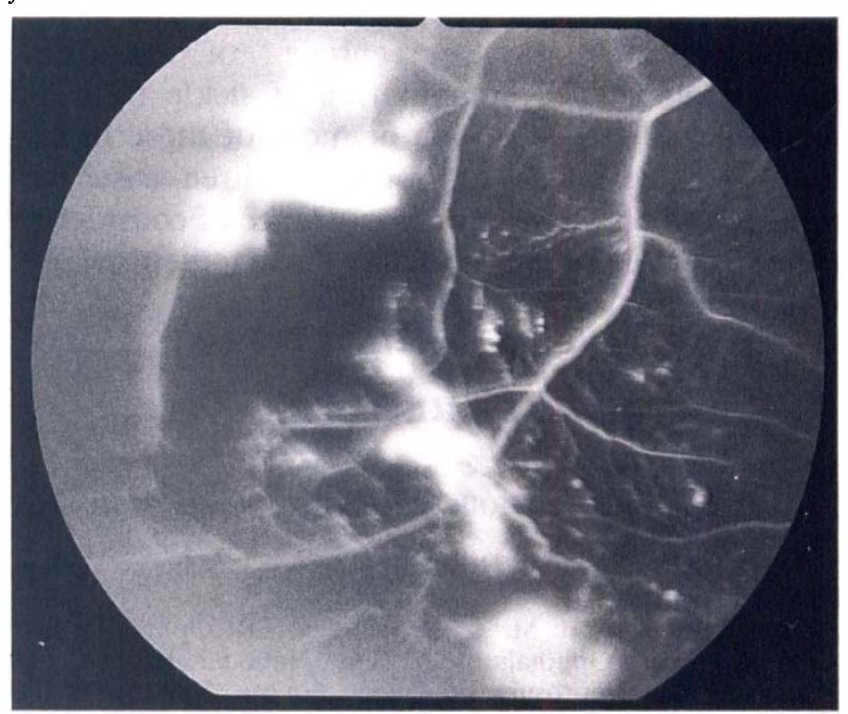

Fig. 6. Case 3. Widespread vascular occlusion and fluorescein leakage from sea-fans. 
6/9 in each eye and she had early nuclear sclerotic cataracts. Fundal examination showed a few scattered microaneurysms at the posterior poles and marked peripheral retinal vascular occlusion and ischaemia with perfused and infarcted sea-fans (Fig. 3 ). This was confirmed on fluorescein angiography (Fig. 4). Haemoglobin electrophoresis indicated HbAS sickle trait (HbS 36.1\%) and her glycosylated haemoglobin was $11.8 \%$.

\section{Case 3}

A 63-year-old Jamaican woman with diet-controlled non-insulin-dependent diabetes diagnosed 2 years previously was referred with slightly raised intraocular pressures. She was a non-smoker and had hypertension which was well controlled on bisiprolol and nifedipine. The IOP was found to be normal and there was no evidence of diabetic retinopathy. Visual acuity was $6 / 6$ in both eyes.

At 1 year's follow-up she was noted to have early background diabetic retinopathy with hard exudates at the right posterior pole. One year later she complained of sudden loss of central vision in the left eye and was found to have a dense epiretinal membrane overlying the left macula reducing the visual acuity to counting fingers. There were also marked sea-fan neovascular fronds in the temporal periphery of both eyes (Fig. 5). Fluorescein angiography confirmed the neovascularisation and demonstrated widespread peripheral vascular occlusion (Fig. 6). Subsequent haemoglobin electrophoresis identified HbAS sickle trait with $31.2 \% \mathrm{HbS}$. Her glycosylated haemoglobin was $6.3 \%$.

\section{DISCUSSION}

The sickle haemoglobinopathies are a group of recessively inherited single gene defects. The commonest abnormalities are a substitution of valine in $\mathrm{HbS}$ and lysine in $\mathrm{HbC}$ for glutamic acid at position 6 of the $\beta$ peptide chain in the normal $\mathrm{HbA}$. These abnormal haemoglobins can, under certain conditions, polymerise and cause erythrocytes to assume a sickled shape, rendering them less deformable. The gene for HbS is inherited recessively and approximately $0.4 \%$ of North American Afro-Caribbeans are homozygous (sickle cell disease). Approximately 9\% are heterozygous and are described as having sickle trait. ${ }^{1}$

A normal erythrocyte can pass through blood vessels smaller than its own diameter because of its ability to alter its discoid shape. Similarly, normal erythrocytes measuring 6-7 $\mu \mathrm{m}$ in diameter can pass through the endothelial trabeculae via pores of 2.5-3.5 $\mu \mathrm{m}$, and into the canal of Schlemm, through pores of $1.0-1.8 \mu \mathrm{m}$ in diameter. ${ }^{7}$ Sickled erythrocytes cannot pass through small-diameter capillaries or the trabecular meshwork. ${ }^{6,7}$ The complement of
$\mathrm{HbA}$ in sickle trait patients was thought to offer protection against the sickling process. However, even heterozygous red cells may sickle in conditions of partial deoxygenation since the mean corpuscular haemoglobin concentration usually exceeds the solubility of deoxygenated haemoglobin., 6

In 1940, Ham and Castle ${ }^{9}$ suggested that the sickling process begins when erythrostasis occurs in the peripheral blood, leading to increased capillary transit time, decreased oxygen tension and subsequently more sickling of erythrocytes. Factors now known to cause increased haemoglobin deoxygenation and therefore increased sickling include low $\mathrm{pO}_{2}$ and $\mathrm{pH}$, high $\mathrm{pCO}_{2}$, diphosphoglycerate, temperature and blood viscosity plus prolonged capillary transit time. ${ }^{6}$ These factors shift the oxygen dissociation curve to the right causing reduced affinity for oxygen in an already compromised haemoglobin molecule.

The ocular manifestations of sickle cell disease are believed to be the result of sickling of erythrocytes within small vessels leading to vascular occlusion, ischaemia and then neovascular proliferation. Fundus changes in sickle cell anaemia were first described by Cook in $1930 .{ }^{10}$ Following this, various authors went on to describe retinal microaneurysms, retinal and vitreous haemorrhages and vascular tortuosity in sickle cell disease $\mathrm{e}^{11,12}$ and in 1954 Henry and Chapman ${ }^{12}$ recognised the existence of retinitis proliferans in sickle cell anaemia.

Despite some reports to the contrary, ${ }^{3,4}$ in 1959 Lieb et $a .^{2}$ concluded that patients with sickle trait demonstrate minor or no fundal changes, and this view would appear to have gained widespread acceptance. Visual loss in patients with sickle trait has been reported, but almost always in conjunction with other precipitating factors. In 1955 Kabakow et $a l .{ }^{13}$ described bilateral central retinal artery occlusions in a patient with sickle trait, systemic lupus erythematosus and active tuberculosis, and in 1967 Conrad and Penner ${ }^{14}$ reported central retinal artery occlusion in a 32-year-old airline pilot with HbAS. In 1970 Stein and Gay ${ }^{15}$ described bilateral central retinal artery occlusions in a 6-month-old baby with $\mathrm{HbAS}$, severe infection, acidosis and dehydration.

Nagpal et al..$^{5}$ described 7 patients with sickle trait and vasoproliferative retinopathy; however, all 7 also had some evidence of associated systemic disease including sarcoid, diabetes, tuberculosis and syphilis. They suggested that the systemic disease in some way caused unfavourable conditions which led to enhanced sickling in each of their cases. McMillan et $a l .{ }^{16}$ observed that there is reduced erythrocyte deformability in diabetes mellitus. He found that this was due to increased intra-erythrocyte viscosity and suggested that this could be the result of increased intracellular haemoglobin A1c. Raised 
IOP secondary to traumatic hyphaema in sickle trait has been described ${ }^{17,18}$ and there have been four reports between 1972 and 1976 of central retinal artery occlusion in these circumstances. ${ }^{19-21}$ Radius and Finkelstein ${ }^{21}$ reported visual deterioration to no perception of light in one patient following mannitol administration and suggested that osmotically induced hyperviscosity contributed to the sickling event. Despite the failure of conventional therapy in reducing IOP, two of these cases responded well to rapid lowering of IOP by anterior chamber paracentesis with good visual outcome after initial total visual loss.

Goldberg ${ }^{17}$ investigated a small number of sickle trait patients with traumatic hyphaema and elevated IOP. $\mathrm{He}$ found that the percentage of sickled erythrocytes was much higher $(9.4-20 \%)$ in the aqueous than in venous blood $(0-1.0 \%)$. He suggested that the relatively isolated, stagnant environment in the anterior chamber unfavourably influenced the behaviour of erythrocytes in sickle trait and implicated the relatively high concentration of ascorbic acid in aqueous humour. It is suggested that, as a reducing agent, aqueous humour ascorbate promotes the conversion of haemoglobin $\mathrm{S}$ to its polymerised form, causing sickling.

The first case described here (case 1) demonstrated a non-neovascular retinopathy following a prolonged episode of raised IOP after traumatic hyphaema. The IOP did respond to osmotic agents, albeit slowly, and the peripheral retina was still not perfused several weeks later. The fluorescein angiogram demonstrates this peripheral occlusion with a border very suggestive of sickle retinopathy. These changes are not normally induced by trauma and the only apparent contributory factor in this patient appears to be the haemoglobinopathy. It could be argued, and indeed was suggested by Goldberg, ${ }^{17}$ that controlled anterior chamber paracentesis would have avoided the risk of further sickling secondary to osmotically induced hyperviscosity. Two of the cases described here (cases 2 and 3) had typical proliferative sickle retinopathy associated with diabetes mellitus.

Retinopathy in sickle trait associated with trauma or systemic disease would appear to be a recurrent theme. There would seem to be little doubt that, in combination with a precipitating factor, sickle trait can give rise to sight-threatening sickle-related complications. In the cases described here, unfavourable conditions have led to circumstances in which increased sickling is likely to occur. It is essential to perform haemoglobin electrophoresis on all individuals from ethnic groups at risk from sickle disease with traumatic hyphaema. Retinal and optic nerve head perfusion may be seriously compromised by raised IOP in sickle trait, and therefore careful monitoring of the IOP is essential. Care must also be taken with the use of carbonic anhydrase inhibitors and osmotic therapy. The increased plasma tonicity, the coincident vascular stasis and increased IOP may precipitate vascular occlusions in patients with sickle trait. ${ }^{21}$ Conversely, retinopathy in patients with sickle trait in the absence of raised IOP or a history of trauma should prompt a thorough search for coexisting systemic disease such as diabetes or hypertension.

\section{CONCLUSION}

Sickle retinopathy in sickle trait does occur. However, almost all the cases reported in the literature have some precipitating factor which presumably promoted sickling of red blood cells. It is essential to exclude sickle cell disease or trait in all at-risk patients with hyphaema and to monitor the IOP carefully. Retinopathy in sickle trait in the absence of raised IOP or a history or trauma should lead to a thorough search for other systemic disease such as diabetes or hypertension.

The authors would like to thank Mr I. K. Luke and Mr R. L. Coakes for allowing us to examine and photograph their patients. Mr C. Clements and Mr R. Dewhurst for the fundus photography and Professor A. C. Bird for reviewing the fluorescein angiograms.

Key words: Raised intraocular pressure, Retinopathy, Sickle trait.

\section{REFERENCES}

1. Myerson RM, Harrison E, Lohmuller HW. Incidence and significance of abnormal haemoglobins. Am J Med 1959;26:543.

2. Lieb WA, Geeraets WJ, Guerry D III. Sickle cell retinopathy: ocular and systemic manifestations of sickle cell disease. Acta Ophthalmol (Copenh) 1959;58(Suppl):3-45.

3. Isbey EK Jr, Clifford GO, Tanaka KR. Vitreous haemorrhage. Am J Ophthalmol 1958;45:870-9.

4. Kennedy JJ, Cope CB. Intraocular lesions associated with sickle cell disease. Arch Ophthalmol 1947;58:1638.

5. Nagpal KC, Asdourian GK, Patrianakos D, et al. Proliferative retinopathy in sickle-cell trait. Arch Intern Med 1977;137:325-8.

6. Dean J, Schechler AN. Sickle-cell anaemia: molecular and cellular basis of therapeutic approaches. N Engl J Med 1978;299:753, 804-11, 863-70.

7. Inomata H, Bill A, Smelser G. Aqueous humour pathways through the trabecular meshwork and into Schlemm's canal in the cynomolgus monkey (Macaca irus): an electron microscope study. Am J Opthalmol 1972;73:760-89.

8. Harris JW. The role of physical and chemical factors in the sickling phenomenon. Prog Hematol 1959;2:47109.

9. Ham TH, Castle WB. Relation of increased hypotonic fragility and of erythrostasis in the mechanism of hemolysis in certain anaemias. Trans Assoc Am Physicians 1940;55:127-32.

10. Cook WC. A case of sickle cell anaemia with 
associated subarachnoid haemorrhage. J Med 1930; 11:541.

11. Hannon JF. Vitreous haemorrhage associated with sickle cell haemoglobin C disease. Am J Ophthalmol 1956;42:707-12.

12. Henry MD, Chapman AZ. Vitreous haemorrhage and retinopathy associated with sickle-cell disease. Am J Ophthalmol 1954;38:204-9.

13. Kabakow B, Van Weimokly SS, Lyons HA. Bilateral central retinal artery occlusion: occurrence in a patient with cortisone treated systemic lupus erythematosus, sickle-cell trait and active pulmonary tuberculosis. Arch Ophthalmol 1955;54:670-6.

14. Conrad WC, Penner R. Sickle-cell trait and central retinal artery occlusion. Am J Ophthalmol 1967;63: 465-8.

15. Stein MR, Gay AJ. Acute chorioretinal infarction in sickle-cell trait: report of a case. Arch Ophthalmol 1970;84:485-90.
16. McMillan DE, Utterback NG, La Puma J. Reduced erythrocyte deformability in diabetes. Diabetes 1978;27:895-901.

17. Goldberg MF. The diagnosis and treatment of secondary glaucoma after hyphema in sickle-cell patients. Am J Ophthalmol 1979;87:43-9.

18. Wax MB, Ridley ME, Magargal LE. Reversal of retinal and optic disc ischemia in a patient with sickle-cell trait and glaucoma secondary to traumatic hyphema. Ophthalmology 1982;89:845-51.

19. Michelson PE, Pfaffenbach D. Retinal arterial occlusion following ocular trauma in youths with sickle-trait hemoglobinopathy. Am J Ophthalmol 1972;74:494-7.

20. Sorr EM, Goldberg RE. Traumatic central retinal artery occlusion with sickle cell trait. Am J Ophthalmol 1975;80:648-52.

21. Radius RL, Finkelstein D. Central retinal artery occlusion (reversible) in sickle trait with glaucoma. $\mathrm{Br}$ J Ophthalmol 1976;60:428-30. 